\title{
Prognostic significance of the size and number of lymph nodes on pre and post neoadjuvant chemotherapy CT in patients with pNO esophageal squamous cell carcinoma: a 5-year follow-up study
}

\author{
Yong-Kun Chi ${ }^{1}$, Ying Chen ${ }^{1}$, Xiao-Ting $\mathrm{Li}^{1}$ and Ying-Shi Sun ${ }^{1}$ \\ ${ }^{1}$ Key Laboratory of Carcinogenesis and Translational Research (Ministry of Education), Department of Radiology, Peking \\ University Cancer Hospital \& Institute, Beijing 100142, China \\ Correspondence to: Ying-Shi Sun, email: sys27@163.com \\ Keywords: esophageal cancer, pNo, survival, computed tomography, neoadjuvant chemotherapy \\ Received: March 22, $2017 \quad$ Accepted: April 28, $2017 \quad$ Published: June 27, 2017 \\ Copyright: Chi et al. This is an open-access article distributed under the terms of the Creative Commons Attribution License 3.0 \\ (CC BY 3.0), which permits unrestricted use, distribution, and reproduction in any medium, provided the original author and source \\ are credited.
}

\section{ABSTRACT}

The prognosis of patients with esophageal cancer improves by using neoadjuvant chemotherapy (NAC). More patients obtain pathological NO staging (pNO) after surgery. The heterogeneity of prognosis of these patients poses a great challenge of customizing therapeutic strategies for individual patients. The signs of lymph nodes on both pre and post NAC computer tomography (CT) scan can provide more information for evaluation. Therefore, we investigated a new approach to lymph node (LN)-survival analysis by using pre-/post-NAC CT in pNO esophageal cancer. 79 patients undergone curative resection after NAC obtained pNO staging. The long and short axis diameter of maximal lymph node (MaxLN) and LN number on pre-/postNAC CT scans were recorded and assessed for predicting survival by univariate and multivariate survival analysis. The prognosis of patients with esophageal cancer was correlated with the LN size and number on pre-/post-NAC CT. The LN number on preNAC CT and short-axis diameter of MaxLN on post-NAC CT remained the independent predictor of overall survival. By using these two factors as classification criterion, NOb group included patients with LN number $>4$ on pre-NAC CT or short-axis diameter of MaxLN >7 mm on post-NAC CT and the rest patients were included in NOa group. NOa group had a significantly better overall survival than NOb group (5-year survival rate: 75.2\% vs. 32.6\%). The size and number of lymph node on pre-/post-NAC CT were reliable and important prognostic factors in patients with pNO esophageal cancer. This new criterion could distinguish these patients into NOa and NOb, according to different prognosis.

\section{INTRODUCTION}

Recent treatment paradigms of esophageal cancer tend to evolve into a multimodality approach to management including surgical resection and preoperative or definitive chemoradiation therapy [1]. Increasingly, neoadjuvant chemotherapy (NAC) is becoming the neoadjuvant treatment of choice for patients with resectable esophageal cancer [2]. A number of these patients obtain ypN0 after neoadjuvant chemotherapy. Although the $\mathrm{N}$ classification is the most important prognostic factor in esophageal cancer because patients without lymph node involvement have a better prognosis than those with nodal involvement [3], we find that these patients presented different survival benefit after NAC downstaging occurrence in clinical follow-up. Thus, we wonder what other factors can be indicators of prognosis in patients with $\mathrm{pN} 0$ esophageal cancer. More pathological indicators are not available for $\mathrm{pN} 0$ patients except $\mathrm{T}$ 
staging. However, the characteristic of lymph nodes before surgery is revealed on the pre- and post-NAC CT.

The size of pathological lymph nodes is a wellknown prognostic factor in esophageal cancer, so nodal size is a criterion for predicting nodal involvement. Unlike the sixth edition of TNM cancer staging manual, the new $\mathrm{N}$ classification was determined by the number of metastasis lymph nodes [4]. The change of $\mathrm{N}$ staging suggests that number of lymph nodes can be important indicator of prognosis. Furthermore, we demonstrate that $\mathrm{CT}$ is an effective tool for measuring the size and counting the total number of lymph nodes [5]. In our prior study, we found that the characteristic of lymph nodes on pretreatment CT was related to the patients' prognosis in other gastrointestinal cancer [6].

Therefore, we decided to review characteristic of lymph nodes on pre- and post-NCA CT for assessing prognosis of ypN0 patients with esophageal squamous cell carcinoma. Further, we investigate a new approach to CT lymph node (LN)-survival analysis for 5 years follow-up in patients with esophageal carcinomas.

\section{RESULTS}

One hundred and thirty three patients undergone curative resection after neoadjuvant chemotherapy were studied. 79 patients obtaining pN0 staging after surgery were included in the follow up study (Figure 1). There were 59 men and 20 women in the study, with a mean age of 59.87 years (range 42-75). More details of patients' characteristics and therapeutic regimens were listed in Table 1.

The distribution of postoperatively pathological T stages was as follows: 16 patients belonged to pT0, 6 patients to pT1a, 11 patients to $\mathrm{pT} 1 \mathrm{~b}, 19$ patients to pT2, 25 patients to $\mathrm{pT} 3$, one patient to $\mathrm{pT} 4 \mathrm{a}$ and one patient to pT4b.

Sixty-one percent of patients (48 of 79 patients) remained alive, at the last follow-up. The overall 1-year, 3 -year and 5-year survival rate were $96.2 \%, 68.9 \%$ and $58.9 \%$ for all 79 patients.

\section{Univariate survival analysis}

The results of univariate survival analysis were listed in Table 2. For age and sex of the patients, pathological differentiation grade, tumor location, NAC scheme, pathological tumor regression grading, number of lymph nodes analyzed, cT and $\mathrm{cN}$ staging, univariate survival analysis did not show any factor related to the OS and DFS.

Although pT was found significant for overall survival, only pT4 patients showed statistically poorer OS than other pT stages when we conducted multiple comparisons among $\mathrm{pT}$ stages.
Among all the image characteristics, LN number and long diameter of MaxLN on pre-NAC CT were related to the OS and DFS. On post-NAC CT, both size and number of lymph node were demonstrated as prognostic factors significantly.

\section{Multivariate survival analysis}

Multivariate survival analysis, including all statistically significant prognostic factors mentioned in univariate analysis ( $p$ value less than or equal to 0.05 ), was performed to determine the independent prognostic factors for $\mathrm{pN} 0$ esophageal squamous cell carcinoma. The pathologic $\mathrm{T}$ staging was also included in the analysis. Multivariate analysis by Cox proportional hazard model showed that LN number on pre-NAC CT and LN size on post-NAC CT were most important independent prognostic factors $(\mathrm{HR}=1.137,95 \% \mathrm{CI}$ : 1.041 to 1.240 ; $\mathrm{HR}=1.083$, 95\%CI: 1.002 to 1.171 ) (Table 3). Max LN short diameter was better than long diameter in predicting overall survival.

\section{Combined criterion for prognosis assessment estimated on CT}

We combined these two factors as criterion in order to distinguish the different prognosis for $\mathrm{pN} 0$ patients with esophageal squamous cell carcinoma. We chose median values ( 4 and $7 \mathrm{~mm}$ ) as cutoff points, the patients were divided into two groups. N0b group included patients with $\mathrm{LN}$ number $>4$ on pre-NAC CT or short-axis diameter of MaxLN>7 mm on post-NAC CT and the rest of $\mathrm{pN} 0$ patients were included in N0a group (Figure 1). The 1-year, 3-year and 5-year survival rates of the two groups were listed in Table 4. The 5-year survival rate was $75.2 \%$ and $32.6 \%$ in two group patients respectively, and difference of overall survival time was statistically significant $(\mathrm{P}<0.001)$.

Patients in $\mathrm{pN0a}$ group $(\mathrm{n}=50$, median survival time not reached) survived longer (Figure 2). The median survival time of remaining patients in pN0b group $(n=29)$ was only 43 months. Moreover, this indicator derived from two preoperative CT examinations provided satisfactory predictability for prognosis. See Figure 3, Figure 4.

\section{DISCUSSION}

\section{Different influence between NOa and N0b}

Esophageal cancer staging is changing gradually and has undergone several revisions with the emergence of new prognostic factors. The post-operative pathological stage is widely accepted to be the best prognostic factor. But the prognosis of patients with $\mathrm{pN} 0$ staging was not discussed in previous study. According to the data of this study, none of $\mathrm{cT}, \mathrm{cN}$ and $\mathrm{pT}$ staging 
was very useful prognostic predictor for these patients. Thus, it suggested that more factors should be considered for predicting overall survival as we could not obtain accurate prediction for $\mathrm{OS}$ in $\mathrm{pN} 0$ patients. In clinical routine follow-up data, some pN0 patients appeared new metastatic lymph nodes after the surgery. The patients' survival seemed different within all pN0 patients. Screen out this worse prognostic part of $\mathrm{pN} 0$ patients may change the treatment plan.
The results of our study suggested that the size and number of lymph nodes on pre- and post-NAC CT may help us to stratify esophageal squamous cell carcinoma patients with pN0 stage into prognostically different groups.

According to the result of survival analysis, we combined the best two factors into a new criterion, which could distinguish N0a and N0b groups. Because of low accuracy of CT for estimating lymph node metastasis

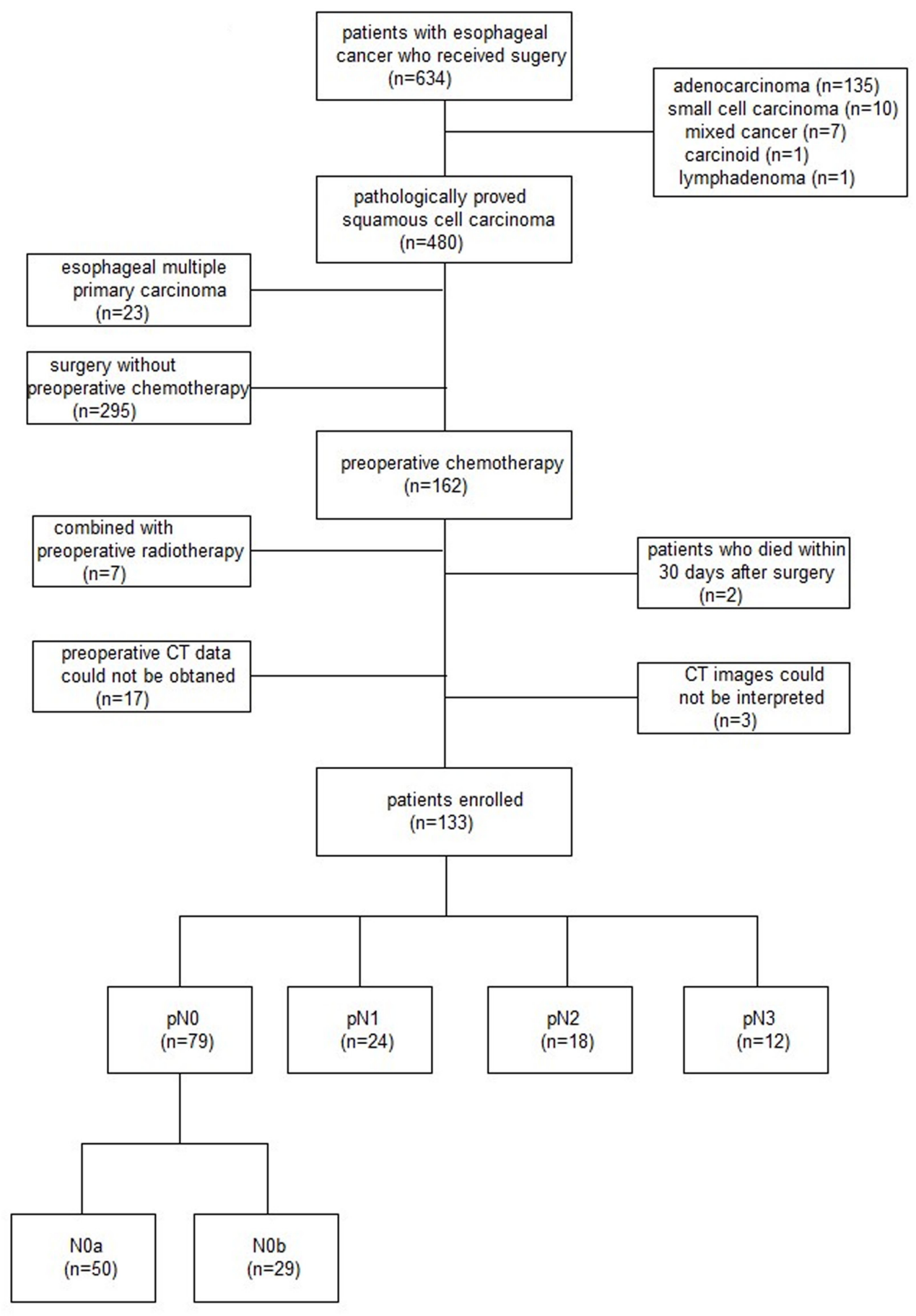

Figure 1: Flow chart of patient enrollment. 
Table 1: Summary of patient characteristics and therapeutic regimen

\begin{tabular}{|c|c|c|}
\hline Patient character $(n=79)$ & & Description \\
\hline Age & & $60 \pm 8(42$ to 75$)$ \\
\hline \multirow[t]{2}{*}{ Sex } & Male & $59(74.7 \%)$ \\
\hline & Female & $20(25.3 \%)$ \\
\hline \multirow[t]{9}{*}{ cTNM stages } & T3N0M0 & $9(11.4 \%)$ \\
\hline & $\mathrm{T} 2 \mathrm{~N} 1 \mathrm{M} 0$ & $10(12.7 \%)$ \\
\hline & $\mathrm{T} 1 \mathrm{~N} 2 \mathrm{M} 0$ & $1(1.3 \%)$ \\
\hline & T3N1M0 & $21(26.6 \%)$ \\
\hline & $\mathrm{T} 3 \mathrm{~N} 2 \mathrm{M} 0$ & $5(6.3 \%)$ \\
\hline & T4aN0M0 & $3(3.8 \%)$ \\
\hline & T4aN1M0 & $17(21.5 \%)$ \\
\hline & T4aN2M0 & $11(13.9 \%)$ \\
\hline & T4aN3M0 & $2(2.5 \%)$ \\
\hline \multirow[t]{3}{*}{ Pathological differentiation } & Well differentiated & $20(25.3 \%)$ \\
\hline & Moderately differentiated & $41(51.9 \%)$ \\
\hline & Poorly differentiated & $18(22.8 \%)$ \\
\hline \multirow[t]{4}{*}{$\begin{array}{l}\text { Neoadjuvant chemotherapy (NAC) } \\
\text { scheme }\end{array}$} & 1 cycle & $14(17.7 \%)$ \\
\hline & 2 cycles & $50(63.3 \%)$ \\
\hline & 3 cycles & $7(8.9 \%)$ \\
\hline & 4 cycles & $8(10.1 \%)$ \\
\hline \multirow[t]{4}{*}{$\begin{array}{l}\text { Pathological tumor regression grading } \\
\text { (TRG) }\end{array}$} & TRG0 & $15(19.0 \%)$ \\
\hline & TRG1 & $22(27.8 \%)$ \\
\hline & TRG2 & $9(11.4 \%)$ \\
\hline & TRG3 & $33(41.8 \%)$ \\
\hline Number of lymph nodes analyzed & & $18 \pm 9(6$ to 48$)$ \\
\hline
\end{tabular}

cTNM stages=clinical TNM stages; NAC scheme=neoadjuvant chemotherapy scheme; TRG=tumor regression grading.

[7], some patients without lymph node involvement in N0a group may be overstaging by pre-treatment CT. So, these patients had better prognosis than patients with extensive lymph node metastasis before treatment. But this factor did not influence all the patients in N0a group. In a word, esophageal cancer with better biological behavior indicated the patients had better prognosis. Our findings confirmed the correlation between severity of LN infiltration and characteristics of lymph node on CT, which was selected as one of the biomarkers. On the other hand, some hazards of lymphadenopathy recurrence were involved in NOb group, which made their survival time similar to patients with pN1 staging. For example, the micro-metastasis of lymph node mentioned in recent pathological literatures may be an important hazard [8]. However, normal-sized lymph nodes which contain microscopic metastatic foci cannot be differentiated from nonmetastatic lymph nodes at $\mathrm{CT}$ and can lead to understaging [9].

We also compared the OS of pNOb patients with that of $\mathrm{pN} 1$ patients in the same study population (Figure 2 ). OS of these two groups were not different statistically $(p=0.801)$. Thus, the patients in N0b group may need more aggressive treatment after surgery. We thought that the pre- and post-NAC CT imaging could influence treatment strategies of patients with esophageal squamous 
Table 2: Univariate analysis of prognostic factors according to OS and DFS

\begin{tabular}{|c|c|c|c|c|c|c|c|}
\hline \multirow{2}{*}{ Prognostic factor } & \multirow{2}{*}{$\begin{array}{l}\text { Number of patients } \\
\qquad(n=79)\end{array}$} & \multicolumn{3}{|c|}{ Overall survival } & \multicolumn{3}{|c|}{ Disease-free survival } \\
\hline & & Rate & $95 \%$ CI & P value & Rate & $95 \%$ CI & P value \\
\hline $\operatorname{Age}(y)$ & & & & 0.508 & & & 0.825 \\
\hline$\leq 59$ & 42 & 57.6 & $38.8-76.4$ & & 60.6 & $45.5-75.7$ & \\
\hline$\geq 60$ & 37 & 52.6 & $35.2-70.0$ & & 54.8 & $37.4-72.2$ & \\
\hline Sex & & & & 0.191 & & & 0.663 \\
\hline Male & 59 & 45.9 & $25.7-66.1$ & & 57.3 & $43.6-71.0$ & \\
\hline Female & 20 & 68.7 & $47.7-89.7$ & & 59.6 & $37.8-81.4$ & \\
\hline $\begin{array}{l}\text { Pathological } \\
\text { differentiation }\end{array}$ & & & & 0.128 & & & 0.133 \\
\hline $\begin{array}{l}\text { Well } \\
\text { differentiated }\end{array}$ & 20 & 34.3 & $10.6-58.0$ & & 45 & $23.2-66.8$ & \\
\hline $\begin{array}{l}\text { Moderately } \\
\text { differentiated }\end{array}$ & 41 & 61.6 & $45.3-77-9$ & & 62.2 & $46.1-78.3$ & \\
\hline $\begin{array}{l}\text { Poorly } \\
\text { differentiated }\end{array}$ & 18 & 71.4 & $50.2-92.6$ & & 77.4 & $57.8-97.0$ & \\
\hline NAC scheme & & & & 0.461 & & & 0.617 \\
\hline 1 cycle & 14 & 49 & $22.3-75-7$ & & 54.4 & $30.0-81.8$ & \\
\hline 2 cycles & 50 & 56.1 & $36.5-75.7$ & & 64.9 & $50.6-79.2$ & \\
\hline 3 cycles & 7 & 57.1 & $20.4-93.8$ & & 57.1 & $20.4-93.8$ & \\
\hline 4 cycles & 8 & 50 & $15.3-84.7$ & & 50 & $15.3-84.7$ & \\
\hline TRG & & & & 0.361 & & & 0.263 \\
\hline TRG0 & 15 & 52.5 & $26.8-78.2$ & & 52.5 & $26.8-78.2$ & \\
\hline TRG1 & 22 & 71.8 & $52.4-91.2$ & & 71.8 & $52.4-91.2$ & \\
\hline TRG2 & 9 & 33.3 & $-2.0-68-6$ & & 37.5 & $4.0-71.0$ & \\
\hline TRG3 & 33 & 65.7 & $49.2-82.2$ & & 64.5 & $47.4-81.6$ & \\
\hline $\mathrm{cT}$ & & & & 0.273 & & & 0.473 \\
\hline cT1 & 1 & - & - & & - & - & \\
\hline cT2 & 11 & 63.6 & $35.2-92.0$ & & 63.6 & $35.2-92.0$ & \\
\hline cT3 & 34 & 39.1 & $13.0-65.2$ & & 55.2 & $37.0-73.4$ & \\
\hline cT4 & 33 & 67 & $50.1-83.9$ & & 68.3 & $52.0-84.6$ & \\
\hline $\mathrm{cN}$ & & & & 0.810 & & & 0.761 \\
\hline $\mathrm{cNO}$ & 12 & 60.6 & $29.8-91.4$ & & 54.5 & $25.1-83.9$ & \\
\hline $\mathrm{cN} 1$ & 48 & 51 & $32.6-69.4$ & & 61.6 & $46.9-76.3$ & \\
\hline $\mathrm{cN} 2$ & 17 & 56.6 & $31.7-81.5$ & & 58.8 & $35.5-82.1$ & \\
\hline $\mathrm{cN} 3$ & 2 & - & - & & - & - & \\
\hline pT & & & & 0.03 & & & 0.051 \\
\hline pT0 & 16 & 55.6 & $30.9-80.3$ & & 55.6 & $30.9-80.3$ & \\
\hline pT1 & 17 & 68.2 & $45.1-91.3$ & & 61.4 & $37.1-85.7$ & \\
\hline pT2 & 19 & 47 & $14.7-79.3$ & & 61.5 & $39.2-83.8$ & \\
\hline pT3 & 25 & 58.4 & $38.6-78.2$ & & 61.2 & $41.2-81.2$ & \\
\hline pT4 & 2 & 50 & $-19.4-119.4$ & & 50 & -19.4-119.4 & antinued) \\
\hline
\end{tabular}




\begin{tabular}{|c|c|c|c|c|c|c|c|}
\hline \multirow{2}{*}{ Prognostic factor } & \multirow{2}{*}{$\begin{array}{c}\text { Number of patients } \\
\qquad(\mathrm{n}=79)\end{array}$} & \multicolumn{3}{|c|}{ Overall survival } & \multicolumn{3}{|c|}{ Disease-free survival } \\
\hline & & Rate & $95 \% \mathrm{CI}$ & P value & Rate & $95 \% \mathrm{CI}$ & P value \\
\hline Tumor location & & & & 0.157 & & & 0.119 \\
\hline Upper $1 / 3$ & 27 & 43.1 & $22.7-63.5$ & & 44.3 & $24.7-63.9$ & \\
\hline Middle 1/3 & 26 & 43.2 & $6.16-80.2$ & & 60 & $39.0-81.0$ & \\
\hline Lower $1 / 3$ & 26 & 69.2 & $51.4-87.0$ & & 68.7 & $50.7-86.7$ & \\
\hline $\begin{array}{l}\text { LN Number on } \\
\text { pre-NAC CT }\end{array}$ & & & & 0.001 & & & 0.002 \\
\hline$\leq 4$ & 34 & 78.4 & $62.7-94.1$ & & 79.6 & $64.9-94.3$ & \\
\hline$>4$ & 45 & 38.8 & $21.4-56.2$ & & 47.6 & $32.5-62.7$ & \\
\hline $\begin{array}{l}\text { Short-axis } \\
\text { diameter of } \\
\text { MaxLN on pre- } \\
\text { NAC CT }\end{array}$ & & & & 0.240 & & & 0.125 \\
\hline$\leq 9 \mathrm{~mm}$ & 40 & 58.0 & $38.8-77.2$ & & 68.1 & $53.0-83.2$ & \\
\hline$>9 \mathrm{~mm}$ & 39 & 52.2 & $35.0-69.4$ & & 53.2 & $36.3-70.1$ & \\
\hline $\begin{array}{l}\text { Long-axis } \\
\text { diameter of } \\
\text { MaxLN on pre- } \\
\text { NAC CT }\end{array}$ & & & & 0.050 & & & 0.022 \\
\hline$\leq 15 \mathrm{~mm}$ & 40 & 60.5 & $40.5-80.5$ & & 72.1 & $57.2-87.0$ & \\
\hline$>15 \mathrm{~mm}$ & 39 & 49.9 & $33.6-66.2$ & & 49.9 & $33.6-66.2$ & \\
\hline $\begin{array}{l}\text { LN Number on } \\
\text { post-NAC CT }\end{array}$ & & & & 0.005 & & & 0.014 \\
\hline$\leq 4$ & 39 & 73.5 & $58.2-88.8$ & & 71.8 & $56.9-86.7$ & \\
\hline$>4$ & 40 & 39.2 & $21.0-57.4$ & & 45.1 & $28.8-61.4$ & \\
\hline $\begin{array}{l}\text { Short-axis } \\
\text { diameter of } \\
\text { MaxLN on post- } \\
\text { NAC CT }\end{array}$ & & & & 0.006 & & & 0.002 \\
\hline$\leq 7 \mathrm{~mm}$ & 40 & 64.3 & $41.2-87.4$ & & 75.9 & $62.2-89.6$ & \\
\hline$>7 \mathrm{~mm}$ & 39 & 43.5 & $27.0-60.0$ & & 40.6 & $24.3-56.9$ & \\
\hline $\begin{array}{l}\text { Long-axis } \\
\text { diameter of } \\
\text { MaxLN on post- } \\
\text { NAC CT }\end{array}$ & & & & 0.055 & & & 0.025 \\
\hline$\leq 12 \mathrm{~mm}$ & 40 & 59.6 & $38.6-80.6$ & & 70.0 & $55.1-84.9$ & \\
\hline$>12 \mathrm{~mm}$ & 39 & 49.9 & $33.6-66.2$ & & 46.1 & $29.6-62.6$ & \\
\hline LNs analyzed & & & & 0.088 & & & 0.205 \\
\hline$\leq 17$ & 42 & 46.2 & $28.0-64.4$ & & 54.8 & $39.1-70.5$ & \\
\hline$>17$ & 37 & 65.3 & $48.1-82.5$ & & 67.6 & $51.3-83.9$ & \\
\hline
\end{tabular}

NAC scheme=neoadjuvant chemotherapy scheme; $T R G=$ tumor regression grading; $\mathrm{cT}=$ clinical $\mathrm{T}$ stages; $\mathrm{cN}=\mathrm{clinical} \mathrm{N}$ stages; $\mathrm{pT}=$ =pathological $\mathrm{T}$ stages; $\mathrm{LN}=$ lymph node; MaxLN=maximal lymph node. 
Table 3: Multivariate analysis of prognostic factors

\begin{tabular}{lcc}
\hline Prognostic factor & Hazard ratio* & P Value \\
\hline pT & NA & NA \\
LN Number on pre-NAC CT & $1.137(1.041,1.240)$ & 0.004 \\
Long-axis diameter of MaxLN on pre-NAC CT & NA & NA \\
LN Number on post-NAC CT & $1.083(1.002,1.171)$ & NA \\
Short-axis diameter of MaxLN on post-NAC CT & NA & 0.044 \\
Long-axis diameter of MaxLN on post-NAC CT & NA \\
\hline
\end{tabular}

pT=pathological T stages; $\mathrm{LN}=$ lymph node; $\mathrm{MaxLN}=$ maximal lymph node.

$\mathrm{NA}=$ not applicable; hazard ratio not calculated when $\mathrm{P} \geq 0.1$.

*Numbers in parentheses are $95 \%$ confidence intervals.

Table 4: Survival rates of different groups according to combined criteria

\begin{tabular}{lcc}
\hline Group & N0a & N0b \\
\hline $\mathrm{N}$ & 50 & 29 \\
Mean survival (months) & 95.07 & 54.30 \\
1 year survival rate(\%) & 100.0 & 89.7 \\
Standard error & - & 5.7 \\
3 year survival rate(\%) & 85.5 & 41.4 \\
Standard error & 5.1 & 9.1 \\
5 year survival rate(\%) & 75.2 & 32.6 \\
Standard error & 6.6 & 9.1 \\
P value & $<0.001$ & \\
\hline
\end{tabular}

N0a group: LN number $\leqq 4$ on pre-NAC CT and short-axis diameter of MaxLN $\leqq 7 \mathrm{~mm}$ on post-NAC CT. N0b group: LN number $>4$ on pre-NAC CT or short-axis diameter of MaxLN $>7 \mathrm{~mm}$ on post-NAC CT.

cell carcinoma, especially for patients with pN0 staging. The management principle of $\mathrm{pN} 1$ patients might be fit for pNOb stage patients.

\section{LN size on CT scan as independent prognostic factor}

The size of lymph node is always a hot issue in cancer studies. Most studies of gastrointestinal tumors consider nodal size as a criterion for predicting nodal involvement. Lymph nodes of $10 \mathrm{~mm}$ or greater on CT have been defined as metastasis in esophageal cancer $[10,11]$.

For tumor patient, lymph node enlargement is an important feature, which is usually detected on CT examination. The diameter of largest mediastinal lymph nodes is about $12 \mathrm{~mm}$ in healthy population [12]. In contrast, the largest LN diameter detected on post-NAC
CT was $22 \mathrm{~mm}$ of the pN0 esophageal squamous cell carcinoma patients in this study. It demonstrated that the lymph node enlargement was an important change in cancer patients. So, we inferred that the size of lymph node on CT may reflect the severity of esophageal cancer.

We noticed that the short-axis diameter of the largest lymph node on post-NAC CT was one of the indicators of patient survival. In our previous study, the independent prognostic role of LN size was also proved in patients with other gastroenteric cancer [6].

In clinical oncology, lymph node status is one of the most common findings associated with the biological behavior of cancer. LN size remains the strongest independent predictor of survival in patients with esophageal squamous cancer [13]. Larger lymph nodes are more easily to be seen in patients with more aggressive cancer. Thus, the size of lymph nodes on CT scan can reflect the disease progression and patient survival. 


\section{LN number on CT as another predictor of survival}

Some pathological studies demonstrate that the number of metastatic lymph nodes is a significant independent survival indicator in esophageal cancer [14, 15]. The AJCC and UICC seventh edition of the staging manual for cancer in the esophagus and esophagogastric junction describes the number of cancer-positive nodes. Several studies have shown that the $\mathrm{pN}$ classification by number of LNs is superior to the previous $\mathrm{pN}$ classification by the location of the LNs [16-18].

These articles prompted us that LN number on CT could be a prognostic marker, in addition to LN size, in patients with esophageal cancer. In our study, we demonstrate that nodal numbers obtained from preNAC CT can be added to the list of prognostic factors for patient survival. In our previous studies, we also discovered that the combined evaluation of these two factors yields a better prognostic prediction than any other factor.

Not all the lymph nodes detected on CT were metastasis in this study. But the pathologic diagnosis of pretreatment lymph node was not available. Although all the patients were diagnosed as $\mathrm{pN} 0$ staging after surgery, the number of lymph nodes on post-NAC CT was different obviously. The patients with more lymph nodes on CT images presented poor survival in all pN0 patients. So, it suggests that the number of lymph nodes detected on CT is an indirect feature of the aggressiveness of the tumor.

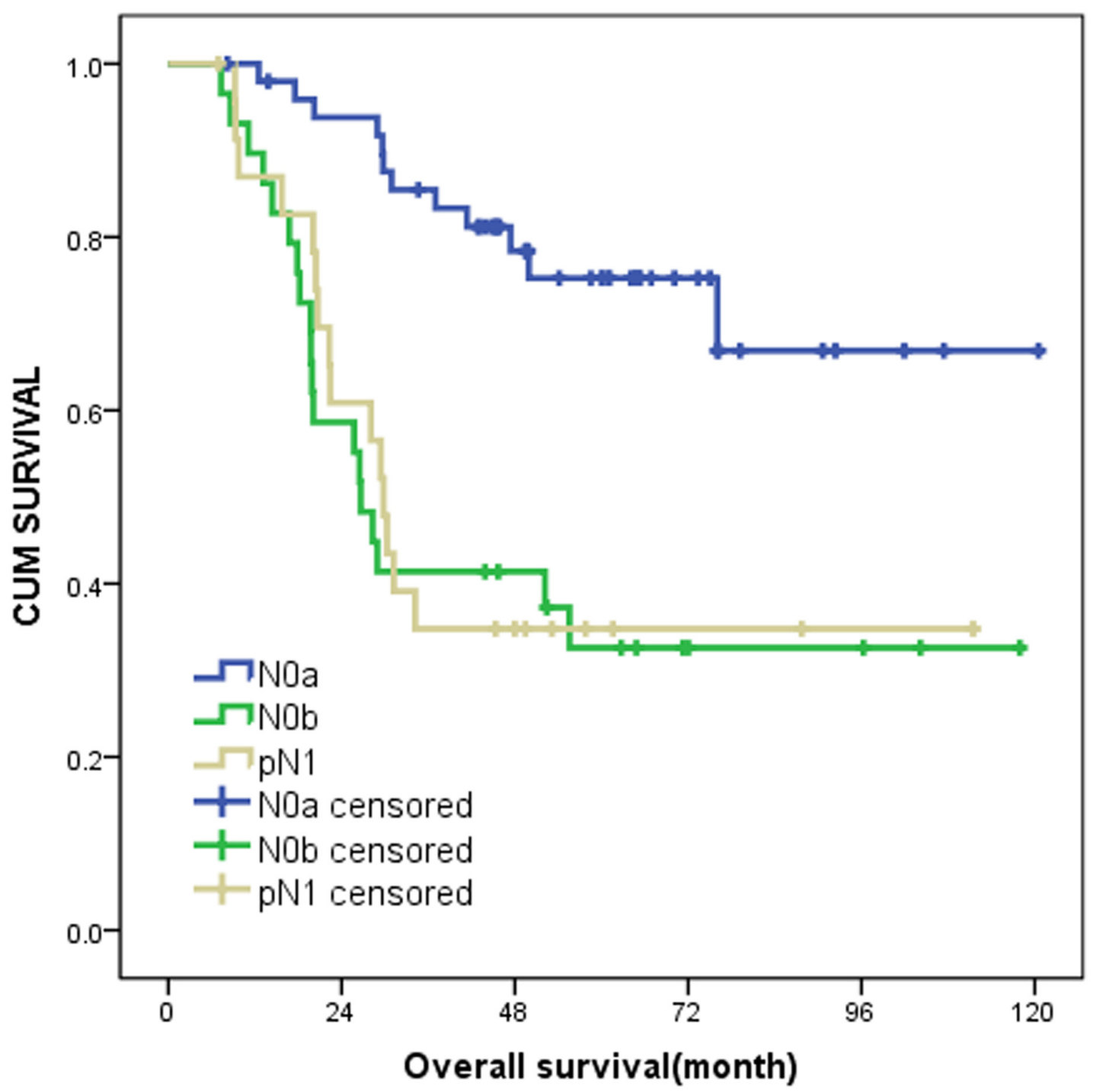

Figure 2: Kaplan-Meier curves of N0a, N0b and pN1 on survival outcomes. (N0a group:LN number $\leqq 4$ on pre-NAC CT and short-axis diameter of MaxLN $\leqq 7 \mathrm{~mm}$ on post-NAC CT. N0b group:LN number $>4$ on pre-NAC CT or short-axis diameter of MaxLN $>7$ mm on post-NAC CT.). 


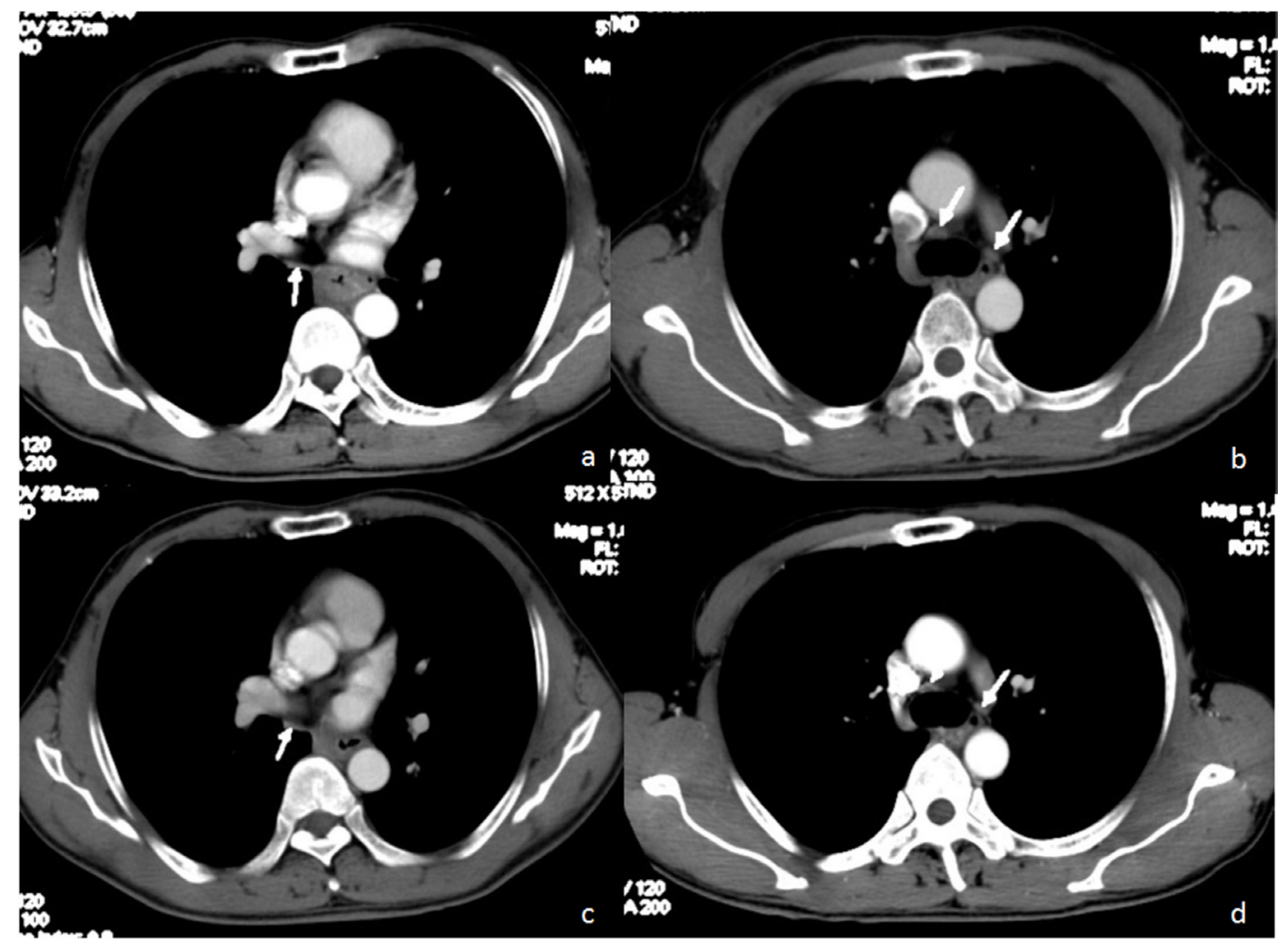

Figure 3: 58 year-old man with good prognosis of esophageal squamous cell carcinoma. Pre-neoadjuvant chemotherapy CT (a, b) showed MaxLN (arrow): 16x5mm, the number of LN (arrow) was 3. Post-neoadjuvant chemotherapy CT (c, d) showed $\operatorname{MaxLN}($ arrow): $13 \times 5 \mathrm{~mm}$, the number of LN (arrow) was $3 . \mathrm{OS}=70.1$ months, DFS=70.1 months.

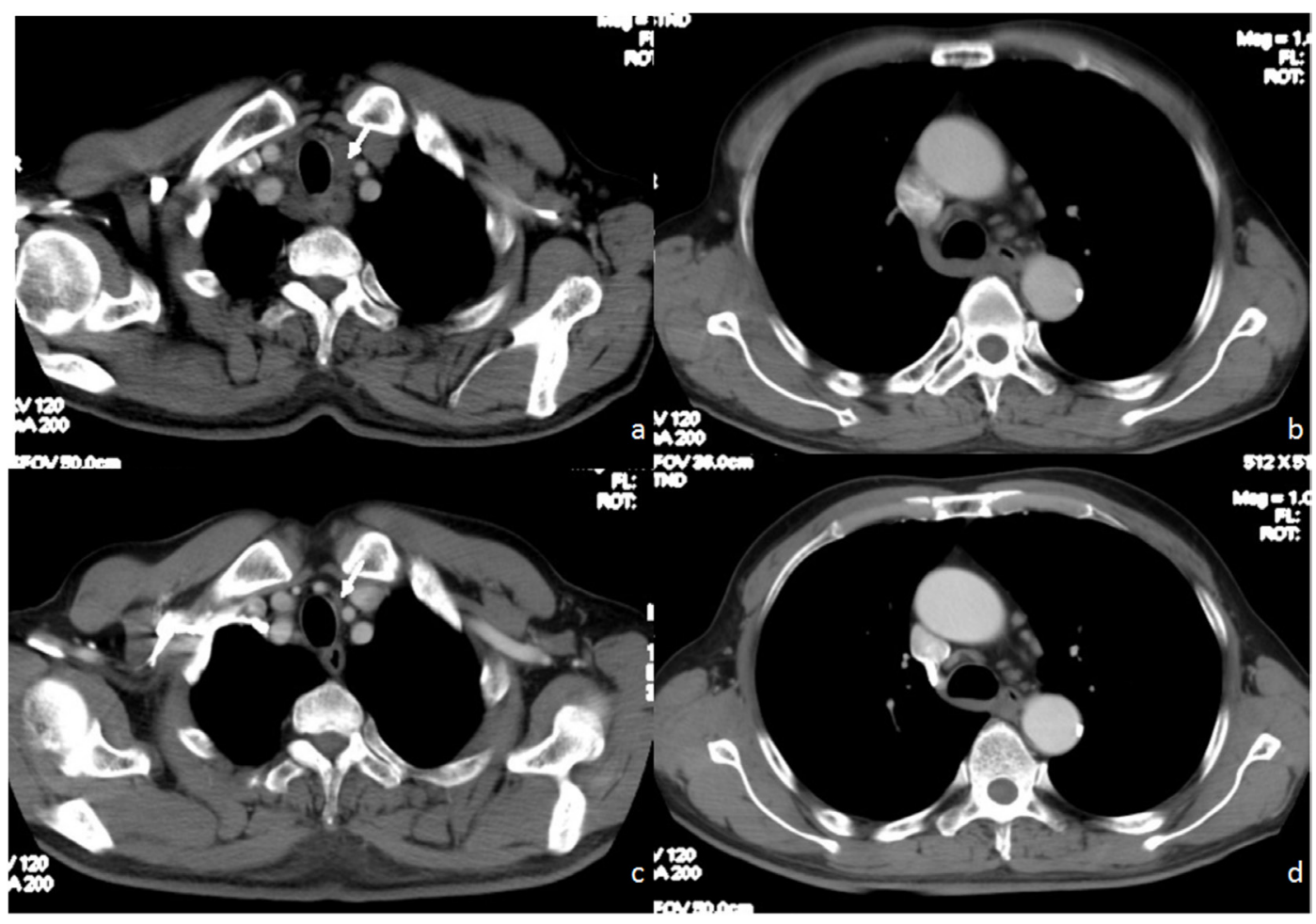

Figure 4: 66 year-old man with poor prognosis of esophageal squamous cell carcinoma. Pre-neoadjuvant chemotherapy CT (a, b) showed MaxLN (arrow): 24x13 mm, the number of LN was 10. Post-neoadjuvant chemotherapy CT (c, d) showed MaxLN (arrow): $10 x 6 \mathrm{~mm}$, the number of LN was 9 . OS=7.3 months, DFS=5.6 months. 
More lymph nodes on CT scans suggest a more adverse prognosis.

\section{Clinical consequences}

Patients with locally advanced esophageal squamous cell carcinoma can benefit from neoadjuvant chemotherapy (NAC) or neoadjuvant chemo-radiation therapy (NCRT). The data from FFCD9901 study [19] suggested NCRT increased incidences of complication and mortality. Many surgeons from China and Japan prefer to choose NAC in treating esophageal squamous cell carcinoma. However most scholars in European and US guessed the preoperative chemoradiotherapy proposed by the CROSS trial was the better preoperative combinational plan [20-21]. In our study, the patients of NOb group did not benefit satisfactorily from NAC alone. So the NCRT plan maybe more effective for these patients.

The characteristics of tumor and lymph node on CT scan can be used to observe the biological behavior of esophageal cancer. It is also revealed in patients with pN0 staging. In this study, our results confirmed that the measurement of size and number of lymph nodes on pre-/post-NAC CT could divide the patients into pNOa and $\mathrm{pNOb}$ groups with different survival. CT imaging features would provide important guidance and clues for the prediction of $\mathrm{pN} 0$ patients' prognosis. A part of $\mathrm{pN} 0$ patients may benefit from the new staging method by CT imaging.

\section{LIMITATIONS}

First, this is a single center study with a small sample. Second, most of patients didn't receive preoperative PET-CT, thus we could not use the result of PET-CT as contrast. Third, we didn't conduct stratification analysis among different pT stages due to the limited sample size.

In conclusion, the size and number of lymph node measured on pre-/post-NAC is a reliable and important prognostic factor in patients with pN0 esophageal squamous cell carcinoma. Therefore, this new criterion can distinguish the $\mathrm{pN} 0$ patients into $\mathrm{N} 0 \mathrm{a}$ and $\mathrm{NOb}$, according to the different prognosis. It also makes the $\mathrm{LN}$ size and number feasible to assess the extent of malignancy, determine prognosis, and aid in the selection of treatment.

\section{MATERIALS AND METHODS}

\section{Patients}

A total of 79 consecutive patients were retrospectively enrolled in this study (Figure 1), who had pathologically proven esophageal squamous cell carcinoma with pN0 staging from November 2005 to December 2011. All the patients were collected from the prospective database of Peking University Cancer Hospital for esophageal cancer.

All the patients were administered pre-NAC contrast enhancement chest $\mathrm{CT}$ at our institution as routine staging examinations and then received chemotherapy followed by surgical R0 resection. Clinical staging was obtained mainly using enhanced CT images since few patients received endoscopic esophageal ultrasonography or PET/ CT. According to the 7th Edition of the UICC-AJCC TNM Classification for Esophageal Cancer [4], patients in this study were all classified as $>\mathrm{cT} 2$ and/or $\mathrm{cN}+$. The post-NAC CT was performed to evaluate the response to neoadjuvant therapies. The pathological staging was performed according to the 7th Edition of the UICCAJCC TNM Classification for Esophageal Cancer [4]. The distribution of cTNM staging, differentiation grade, pathological tumor regression grading (TRG) and number of removed lymph nodes were all listed on Table 1.

Patients were excluded if: a) other pathological types of esophageal cancer than squamous cell carcinoma; b) they underwent other preoperative therapies simultaneously; c) they had history of other malignancy or esophageal multiple primary carcinoma; d) they received R1 or R2 resection; e) they died within 30 days after surgery; or f) enhanced CT images before and after preoperative chemotherapy could not be obtained or interpreted.

In addition, to protect patient privacy, we removed all identifiers from our records at the completion of analyses. The retrospective investigation project has been examined and certified by Ethics Committee of Beijing Cancer Hospital with waiver of the informed consent.

\section{Imaging techniques}

All patients received enhanced $\mathrm{CT}$ scanning within one week before chemotherapy and within one week before surgery. CT examinations were performed with a 64 row helical CT scanner (General Electrical Medical Systems, Milwaukee, WI, Lightspeed VCT). Scans of the chest were performed in the cranio-caudal direction starting from the neck to the renal hilum level. The scans were started $55 \mathrm{~s}$ after intravenous injection of non-ionic contrast material $(1.5 \mathrm{ml} / \mathrm{kg}$ body weight; Omnipaque 300 , GE Healthcare) at a rate of $3 \mathrm{ml} / \mathrm{s}$ by a high pressure injector via the antecubital vein. The following scan parameters were used: tube peak voltage $120-140 \mathrm{KV}$, tube current $300 \mathrm{mAs}$, collimation thickness $1.25 \mathrm{~mm}$, helical pitch 1.5:1. The original data was post-processed at Advantage Workstation 4.2 Image Workstation (General Electrical Medical Systems, Milwaukee, WI), and the coronal and sagittal images were reconstructed using multiplanar reconstruction (MPR) (thickness $0.625 \mathrm{~mm}$ ).

CT images were analyzed on a PACS station by two independent radiologists who were blinded to clinical and histopathologic information. The short and long diameters 
of the largest lymph node were measured on CT scans and were considered as the LN size. The total number of all the visible lymph nodes on CT was considered as the LN number. Any nodule larger than $2 \mathrm{~mm}$ was deemed as a lymph node. The average of the two radiologists' results was used in analysis for short and long diameters. The interpretation of the total number was resolved by consensus if there was discrepancy.

\section{Neoadjuvant chemotherapy and surgery}

Platinum-based 2-drug combination, mainly paclitaxel (175 mg/m2, iv, d1 Q21) and cisplatin (25 mg/ $\mathrm{m} 2 \mathrm{iv}, \mathrm{d} 1-3 \mathrm{Q} 21)$ at a $97 \%(129 / 133)$ proportion. The other 4 cases used nedaplatin $(80 \mathrm{mg} / \mathrm{m} 2$ of body surface area) combined with paclitaxel. Approximately 1-4 neoadjuvant chemotherapy cycles were administered before surgery. Among them, 23, 90, 9, and 11 cases received 1, 2, 3, and 4 cycles, respectively. Surgery was 3-6 weeks after neoadjuvant chemotherapy.

All 133 subjects ( $\mathrm{pN} 0 \& \mathrm{pN}+$ ) underwent radical surgery for ESCC, 114 underwent transthoracic esophagectomy, and 19 underwent transhiatal esophagectomy. Among 114 transthoracic cases, 99 underwent modified Mckeown operation, 10 underwent modified Ivor-Lewis operation, and 5 received trans-left thorax operation (modified Sweet). 111 cases underwent 2-field lymphadenectomy, and 3 underwent 3-field. The number of lymph nodes analyzed was more than six for each patient (Table 1).

\section{Follow-up}

The follow-up consisted of outpatient interviews at 3 month intervals for 2 years, then at 6 month intervals for 3 years, and finally at 12 month intervals until death. Disease-free survival (DFS) was measured from the pre-NAC CT examination date until progression at any site, and patients alive and disease free were censored at the last follow-up. Overall survival (OS) was measured from the pre-NAC CT examination date until esophageal cancer-specific death, and patients alive or dead from other causes were censored at the last follow-up. The follow-up was conducted until June in 2015. The median follow-up time was 64.1 months, ranged from 7.3 to 121 months.

\section{Statistical analysis}

The following parameters from clinical pathological information and pre-/post-treatment CT were chosen as parameters for survival analysis: patient age ( $\leq 59$ vs. $\geq 60$ years), sex (male vs. female), tumor location (upper middle and lower), pT staging, LN number on pre-/posttreatment CT, short-axis and long-axis diameter of MaxLN on pre-/post-treatment CT images.

The overall survival rate of the different groups as well as the median survival time and survival curves were achieved by using the Kaplan-Meier method. Overall differences in the survival curves were analyzed with the log-rank test.

The multivariate Cox proportional hazards model was used to adjust for the influence of prognostic factors. All statistical analyses and graphs were performed by using the Statistical Package for Social Sciences Program, version 18.0 (SPSS, Chicago, IL). For all analyses, $P$ values less than .05 was considered to denote a significant difference.

\section{Abbreviations}

$\mathrm{cT}=$ clinical $\mathrm{T}$ staging; $\mathrm{pT}=$ pathological $\mathrm{T}$ staging; $\mathrm{cN}=$ clinical $\mathrm{N}$ staging; $\mathrm{pN}=$ pathological $\mathrm{N}$ staging; $\mathrm{LN}=$ lymph node; MaxLN=maximal lymph node; $\mathrm{NAC}=$ neoadjuvant chemotherapy; $\mathrm{CT}=$ computer tomography; $\mathrm{TRG}=$ pathological tumor regression grading; $\mathrm{MPR}=$ multiplanar reconstruction; DFS=diseasefree survival; $\mathrm{OS}=$ overall survival; $\mathrm{NCRT}=$ neoadjuvant chemo-radiation therapy.

\section{Author contributions}

Ying-Shi Sun designed the study, Yong-Kun Chi and Ying Chen collected patients, retrieved CT images and conducted measurement, Xiao-Ting Li performed statistical analysis, all authors participated in drafting the paper and approved of the final work.

\section{CONFLICTS OF INTEREST}

All authors confirm that there are no conflicts of interest to declare.

\section{FUNDING}

This work was supported by the National Natural Science Foundation of China (Grant No. 81471640) and Beijing Natural Science Foundation (Grant No. 7172049).

\section{REFERENCES}

1. Korst RJ, Altorki NK. Imaging for esophageal tumors. Thorac Surg Clin. 2014; 14: 61-69.

2. Medical Research Council Oesophageal Cancer Working Group. Surgical resection with or without preoperative chemotherapy in oesophageal cancer: a randomised controlled trial. Lancet. 2002; 359: 1727-1733.

3. Lerut T, Coosemans W, Decker G, De Leyn P, Nafteux P, Van Raemdonck D. Cancer of the esophagus and gastroesophageal junction: potentially curative therapies. Surg Oncol. 2001; 10: 113-122.

4. Edge SB, Byrd DR, Compton CC, Fritz AG, Greene FL, Trotti AI (eds). Esophagus and esophagogastric junction. 
In: AJCC cancer staging manual, 7th edn. New York: Springer. 2009; pp 103-115.

5. Hong SJ, Kim TJ, Nam KB Lee IS, Yang HC, Cho S, Kim K, Jheon S, Lee KW. New TNM staging system for esophageal cancer: what chest radiologists need to know. RadioGraphics. 2014; 34: 1722-1740.

6. Chi YK, Zhang XP, Li J, Sun YS. To be or not to be: significance of lymph nodes on pretreatment CT in predicting survival of rectal cancer patients. Eur J Radiol. 2011; 77: 473-477.

7. Kalantzis N, Kallimanis G, Laoudi F, Papavasiliou E, Gabriel G. Endoscopic ultrasonography and computed tomography in preoperative (TNM) classification of oesophageal carcinoma [abstr]. Endoscopy. 1992; 24(suppl): 653.

8. Prenzel KL, Hölscher AH, Drebber U, Agavonova M, Gutschow CA, Bollschweiler E. Prognostic impact of nodal micrometastasis in early esophageal cancer. Eur J Surg Oncol. 2012; 38: 314-318.

9. Markowitz A, Gerdes H. Diagnosis and preoperative staging of esophageal cancer. In: Posner MC, Vokes EE, Weichselbaum RR (eds) Cancer of the upper gastrointestinal tract. Lewiston: Decker. 2002; pp 23-46.

10. Dorfman RE, Alpern MB, Gross BH, Sandler MA. Upper abdominal lymph nodes: criteria for normal size determined with CT. Radiology. 1991; 180: 319-322.

11. Fultz PJ, Feins RH, Strang JG, Wandtke JC, Johnstone DW, Watson TJ, Gottlieb RH, Voci SL, Rubens DJ. Detection and diagnosis of nonpalpable supraclavicular lymph nodes in lung cancer at CT and US. Radiology. 2002; 222: 245-251.

12. Glazer GM, Gross HB, Quint LE, Francis IR, Bookstein FL, Orringer MB. Normal mediastinal lymph nodes: number and size according to American Thoracic Society mapping. AJR Am J Roentgenol. 1985; 144: 261-265.

13. Dhar DK, Tachibana M, Kinukawa N, Riruke M, Kohno H, Little AG, Nagasue N. The prognostic significance of lymph node size in patients with squamous esophageal cancer. Ann Surg Oncol. 2002; 9: 1010-1016.

14. Chen J, Xu R, Hunt GC, Krinsky ML, Savides TJ. Influence of the number of malignant regional lymph nodes detected by endoscopic ultrasonography on survival stratification in esophageal adenocarcinoma. Clin Gastroenterol Hepatol. 2006; 4: 573-579.
15. Natsugoe S, Yoshinaka H, Shimada M, Sakamoto F, Morinaga T, Nakano S, Kusano C, Baba M, Takao S, Aikou T. Number of lymph node metastases determined by presurgical ultrasound and endoscopic ultrasound is related to prognosis in patients with esophageal carcinoma. Ann Surg. 2001; 234: 613-618.

16. Talsma K, van Hagen P, Grotenhuis BA. Steyerberg EW, Tilanus HW, van Lanschot JJ, Wijnhoven BP. Comparison of the 6th and 7th editions of the UICC-AJCC TNM classification for esophageal cancer. Ann Surg Oncol. 2012; 19: 2142-2148.

17. Mehta SP, Jose P, Mirza A, Pritchard SA, Hayden JD, Grabsch HI. Comparison of the prognostic value of the 6th and 7th editions of the Union for International Cancer Control TNM staging system in patients with lower esophageal cancer undergoing neoadjuvant chemotherapy followed by surgery. Dis Esophagus. 2013; 26: 182-188.

18. Hsu PK, Wu YC, Chou TY, Huang CS, Hsu WH. Comparison of the 6th and 7 th editions of the American Joint Committee on Cancer tumor-node-metastasis staging system in patients with resected esophageal carcinoma. Ann Thorac Surg. 2010; 89: 1024-1031.

19. Mariette C, Dahan L, Mornex F, Maillard E, Thomas PA, Meunier B, Boige V, Pezet D, Robb WB, Le Brun-Ly V, Bosset JF, Mabrut JY, Triboulet JP, et al. Surgery alone versus chemoradiotherapy followed by surgery for stage I and II esophageal cancer: final analysis of randomized controlled phase III trial FFCD 9901. J Clin Oncol. 2014; 32: 2416-2422.

20. van Hagen P, Hulshof MC, van Lanschot JJ, Steyerberg EW, van Berge Henegouwen MI, Wijnhoven BP, Richel DJ, Nieuwenhuijzen GA, Hospers GA, Bonenkamp JJ, Cuesta MA, Blaisse RJ, Busch OR, et al. Preoperative chemoradiotherapy for esophageal or junctional cancer. $\mathrm{N}$ Engl J Med. 2012; 366: 2074-2084.

21. Oppedijk V, van der Gaast A, van Lanschot JJ, van Hagen P, van Os R, van Rij CM, van der Sangen MJ, Beukema JC, Rütten H, Spruit PH, Reinders JG, Richel DJ, van Berge Henegouwen MI, et al. Patterns of recurrence after surgery alone versus preoperative chemoradiotherapy and surgery in the CROSS trials. J Clin Oncol. 2014; 32: 385-391. 